\title{
REGISTRO DE ALTITUD DEL AEDES AEGYPTI EN COLOMBIA
}

\author{
MARCO F. SUAREZ, * MICHAEL J. NELSON. **
}

En Colombia se había considerado que el mosquito Aedes aegypti no habitaba en alturas superiores a los 1.500 metros sobre el nivel del mar $(\mathrm{m} / \mathrm{nm})$. Se disponía de los registros de Oiba (Santander), a $1.400 \mathrm{~m} / \mathrm{nm}$ y con temperatura media de $20^{\circ} \mathrm{C}$ y del Líbano (Tolima), a $1.585 \mathrm{~m} / \mathrm{nm}$ y con temperatura media de $20^{\circ} \mathrm{C}$. (1).

La Dirección de Campañas Directas del Ministerio de Salud a través del Servicio de Erradicación de la Malaria, inició en julio de 1981 una encuesta nacional con miras a delimitar las áreas geográficas de infestación y verificar la presencia del A. aegypti, en zonas en donde nunca se le había encontrado. Hasta noviembre de 1981 se han encuestado 5.308 casas en 55 municipios de los departamentos de Antioquia, Santander y Cundinamarca.

Como resultado preliminar de esta encuesta, presentamos el hallazgo del A. aegypti, en 22 municipios por encima de los 1.600 $\mathrm{m} / \mathrm{nm}$, entre ellos Fusagasugá, (Cundinamarca), a $1.728 \mathrm{~m} / \mathrm{nm}$, ubicado a solo $45 \mathrm{~km}$. de Bogotá y Málaga (Santander), a 2.200 $\mathrm{m} / \mathrm{nm}$. Los índices de infestación de casas con larvas de $A$. aegypti fueron de $21 \%$ y $12.4 \%$ respectivamente. Dados estos índices, es posible descartar la hipótesis de que las infestaciones sean accidentales; lo que ha ocurrido es que el mosquito se ha adaptado a estas altitudes. La campaña anti-Aedes aegypti tendrá que llegar entonces hasta los $2.200 \mathrm{~m} / \mathrm{nm}$. para erradicar o controlar este mosquito en Colombia.

\footnotetext{
* Jefe de Entomología, Servicio de Erradicación de la Malaria, Apartado Aéreo 4851 , Bogotá, Colombia.

* Entomólogo, Organización Panamericana de la Salud/OMS. Proyecto AMRO 0700. Apartado Aéreo 29668 , Bogotá, Colombia.

(1) A. Morales, comunicación personal.
} 